

\title{
An International Exploration of the Effect of Media Portrayals of Postconcussion Management on Concussion Identification in the General Public
}

Ku, C., McKinlay, A., Grace, R. C., Linden, M., \& McLellan, T. (2020). An International Exploration of the Effect of Media Portrayals of Postconcussion Management on Concussion Identification in the General Public. The Journal of head trauma rehabilitation, 35(3), 218-225. https://doi.org/10.1097/HTR.0000000000000547

Published in:

The Journal of head trauma rehabilitation

Document Version:

Peer reviewed version

Queen's University Belfast - Research Portal:

Link to publication record in Queen's University Belfast Research Portal

Publisher rights

Copyright 2020 Lippincott, Williams \& Wilkins. This work is made available online in accordance with the publisher's policies. Please refer to any applicable terms of use of the publisher.

\section{General rights}

Copyright for the publications made accessible via the Queen's University Belfast Research Portal is retained by the author(s) and / or other copyright owners and it is a condition of accessing these publications that users recognise and abide by the legal requirements associated with these rights.

\section{Take down policy}

The Research Portal is Queen's institutional repository that provides access to Queen's research output. Every effort has been made to ensure that content in the Research Portal does not infringe any person's rights, or applicable UK laws. If you discover content in the

Research Portal that you believe breaches copyright or violates any law, please contact openaccess@qub.ac.uk. 


\title{
An international exploration of the effect of media portrayals of post-concussion management on concussion identification in the general public.
}

Ku, C., McKinlay, A., Grace, R.C., McLellan, T. \& Linden, M.

\begin{abstract}
Background: Concussion portrayal in media broadcasts of sporting events may contribute to lack of public understanding regarding concussion.

Methods: 828 participants from Australia, New Zealand and United Kingdom completed a questionnaire assessing concussion knowledge. Participants were randomly assigned to either receive sports return-to-play (RTP) guideline information (RTP group) or not (No-RTP group). Participants viewed 12 short clips from televised rugby games and indicated whether they believed the player in each clip had sustained a concussion. Participants were then informed whether the player was removed, returned, or stayed in the game and again asked if they thought a concussion had occurred.
\end{abstract}

Results: Probability of reporting a likely concussion over all videos was $65.6 \%$. When told a player's possible concussion was managed by removal from the game, participants were more likely to change their response from no (no concussion) to yes (concussion) than from yes to no. When told the player stayed or returned to the game, participants were more likely to change their response from yes (concussion) to no (no concussion) than from no to yes. There was no significant main effect for RTP guideline manipulation or interaction effect with return-to-play information.

Conclusion: Additional player's injury management information influenced participants' judgments of concussion occurrence. Results show that information provided via sports 


\section{Accepted to Journal of Head Trauma Rehabilitation on 01/09/2019}

media broadcasts influenced viewers' perceptions of concussion and appropriate concussion management.

\section{Introduction}

Each year, an estimated 57 million people suffer from a mild traumatic brain injury, also known as concussion. ${ }^{1}$ Despite this high incidence, there is growing evidence to suggest that the general public hold misconceptions about how to recognise and appropriately manage concussive injuries. ${ }^{2}$ It is therefore important to identify sources of misinformation about concussion to determine the most effective channels for improving public understanding. The media is one such source that has been identified as a potentially powerful influence on public perceptions of concussion. ${ }^{3}$ This influence may be particularly salient in contexts where the public are regularly exposed to head injuries and their subsequent management, such as during televised broadcasts of professional sporting events. If the information presented to the public in broadcast sport misrepresents or downplays the severity or consequences of concussion, viewers' decisions regarding post-concussion health-seeking behaviour for themselves or for someone in their care may also be based on incorrect knowledge. This study aimed to examine the influence of representations of potential head injuries in televised sport on judgments and perceptions of concussion within the general public.

Concussion is a commonly occurring injury in contact sports such as American football, ice hockey, and rugby. ${ }^{4}$ American football, for example, accounts for more than $60 \%$ of concussions in organised high school sports in the United States. ${ }^{5}$ Rugby League, hereafter referred to as Rugby, is a highly collisional sport similar to American football that involves two teams competing in full body contact. The overall objective of the game is for the team in possession of the ball to score by carrying the ball over the opponent's goal line before the opposition successfully completes a set of six highly physical defensive tackles. If 


\section{Accepted to Journal of Head Trauma Rehabilitation on 01/09/2019}

the attacking team is not able to score before the set of tackles are complete, possession of the ball is transferred to the opposing team to commence their offensive play. ${ }^{6}$ Rugby in all it's forms is played at a variety of levels in more than 30 countries, and watched by millions of spectators around the world. In Australia for example, over 3.6 million people attended a game during the 2016 National Rugby League (NRL) season, and an estimated 356,000 viewers watched each game on television. ${ }^{7}$ During the grand final, this figure rose to almost 3.7 million viewers. ${ }^{7}$ The growth of online media has also seen a rapid increase in audiences in Australia, with more than 100 million minutes of live game footage streamed on mobile devices during the 2016 season. $^{7}$

Due to the large number of high impact tackles executed during a rugby game, concussive injuries are a common occurrence, with incidence rates estimated to range between 7.5 and 17.5 injuries for every 1000 playing hours. ${ }^{8}$ Given the high rates of injury, internationally recognized return-to-play (RTP) guidelines have been developed to assist the post-concussive management of athletes who sustain a head injury on the field and the decision-making processes related to returning an athlete to play following an injury. ${ }^{9}$ Generally, these guidelines stipulate that players should be withdrawn from the field immediately and prevented from taking part in any high risk activities, including training and competition, for a minimum of 1-4 weeks. ${ }^{10-12}$

Despite the introduction of stringent RTP guidelines, the portrayal of post-concussion management in televised rugby games is often very different, with athletes frequently being shown returning to play within minutes of an injury occurring. ${ }^{13}$ For example, using a surveillance method of televised matches during the 2010/2011 NRL season, McLellan and McKinlay ${ }^{13}$ reported that $31 \%$ of the games showed a player visibly experience a probable concussion. However, only $65 \%$ of these players were shown to leave the ground due to probable concussion, and more than $30 \%$ of players continued to play without receiving 


\section{Accepted to Journal of Head Trauma Rehabilitation on 01/09/2019}

proper treatment. Of the players who did leave the field, almost half were shown to resume playing within the same game. These findings are concerning because concussed athletes who continue to play without treatment or who resume playing prematurely have been shown to have significantly slower reaction times, ${ }^{14}$ leading to an increased risk of more severe postconcussive symptoms and longer recovery times, as well as greater risk of re-injury. ${ }^{15}$ Multiple concussions have been linked to a number of serious long-term consequences including violent behaviour and increased risk of psychiatric disorders, ${ }^{16}$ as well as cognitive impairment in later life. ${ }^{17}$

There are a number of explanations as to why rugby players may continue to play despite appearing to sustain a probable concussion on the field, such as difficulty detecting and diagnosing concussion or concerns about letting teammates down. ${ }^{11}$, ${ }^{18}$ While recent analysis of injury reports in the National High School Sports-Related Injury Surveillance System in the USA suggest that RTP guidelines are being followed, at least at those schools who's athletes are managed by a healthcare team approach, ${ }^{19}$ it is possible that other sports systems and in other countries that RTP guidelines are not as rigorously implemented. Although decisions regarding returning a player to the game ultimately rest with medical personnel and coaching staff, ${ }^{15}$ the televised depiction of poorly managed concussion may have important implications for spectators, whose perceptions and knowledge of concussion are likely to be influenced by what they view on television. For example, if viewers witness a player sustain what appears to be a likely concussion but then see that player remain on the field, they may perceive the concussive injury to be insufficiently serious to warrant medical attention, which may, in turn, reduce the likelihood that viewers will seek medical intervention following an injury to themselves or someone in their care. Similarly, if viewers observe a player with concussion return to the same game following brief treatment on the side lines, they may also assume that it is unnecessary to withdraw from high risk activities 


\section{Accepted to Journal of Head Trauma Rehabilitation on 01/09/2019}

for an extended period of time following a concussion, which again, may have negative implications for the way viewers manage concussive injuries in their own lives.

The manner in which concussion is discussed by sports media during televised sports broadcasts may further compound the potential for misconceptions among viewers. For example, commentators will commonly portray the act of sacrificing one's body for the team as admirable and courageous ${ }^{20,21}$ and describe athletes who endure tremendous pain on the field yet continue to play as heroic. ${ }^{22}$ The underlying message communicated to the viewer through these depictions is that on the sporting field, "digging deep" and playing on through injuries is more important than exercising caution and good injury management. In addition to these more general attitudes within sports media, commentary teams can also be a source of specific misinformation about concussion. Using qualitative analysis, McLellan and McKinlay ${ }^{13}$ reported that commentary teams provided viewers of broadcast rugby games with information that suggested that three-quarters of the players who had experienced a likely concussion continued to play without leaving the field or later returned to the game.

Furthermore, Kennard and colleagues ${ }^{23}$ found that following a concussion on the rugby field, it was much more common for commentators to use dramatic and entertaining language to describe a concussion and a player's reaction to the injury than it was for commentators to convey factual information about player welfare or subsequent medical intervention. It is therefore reasonable to suggest that the way concussion is portrayed and discussed in broadcast sport may contribute to and reinforce incorrect perceptions of concussion and appropriate concussion management within the general viewing public.

\section{The Current Study}

The aim of this study was to examine how the portrayal of a potential concussive injury in televised footage of a professional rugby match could influence judgments and 


\section{Accepted to Journal of Head Trauma Rehabilitation on 01/09/2019}

attitudes towards concussion within the general public. We examined whether providing participants with information on return-to-play guidelines and additional information on how the injury was managed (i.e., whether the player stayed on the field, was removed from the game, or left the field and later returned) resulted in changes to participants' perceptions of whether or not a concussion had occurred.

It was hypothesized that: (1) participant judgements would be influenced by information about player management following an injury to the head; and (2) participants who received information about RTP guidelines would be more likely than participants who did not to change their decision regarding whether a concussion had occurred based on the concussion management information.

\section{Method}

\section{Participants}

A convenience sample of 828 participants (42.4\% female) from New Zealand ( $n=55)$, Australia ( $n=290)$ and the United Kingdom $(n=483)$ aged 18 years or older were recruited via an online survey platform, Qualtrics Panels. ${ }^{24}$ Qualtrics maintain an on-line pool of potential respondents from which respondents who meet the survey criteria could consent to undertake the on-line questionnaire. The regions were selected based on the popularity of rugby and the resulting familiarity participants would have with the sport. All participants gave informed consent. Participants were offered NZ\$10 for completing the survey. Ethics approval was obtained from the University of Canterbury Human Ethics Committee.

\section{Measures}

Demographics. Participants were asked a series of questions that assessed age, gender, location (New Zealand, United Kingdom, or Australia), personal history of concussion, 


\section{Accepted to Journal of Head Trauma Rehabilitation on 01/09/2019}

experience of playing rugby (e.g., never played, played one game, play competitively), and spectator behaviour related to rugby (e.g., never watch, watch more than one game a week).

Participant concussion history and knowledge. Participants were asked if they had ever experienced a concussion, and if so, how many concussions, age at time of first injury, medical attention sought and the mode of injury. Participants were not given any information about concussion so that they presented with current general public knowledge of concussion.

Concussion Reporting Behaviour. To evaluate concussion reporting behaviour, participants were shown 12 video clips (10-20 seconds in length) taken from televised broadcasts of professional rugby games that depicted players experiencing concussion-like events. All videos showed a player experiencing a mechanism of concussion (e.g., being tackled to the ground) but not necessarily a knock to the head. Symptoms of concussion were also present in the videos (e.g., confusion, uncoordinated movements, loss of consciousness). After watching each video, participants were asked to indicate whether the player in the clip had experienced a concussion (yes/no).

Participants were then provided with one of three randomly allocated pieces of additional information on how the player's concussion was managed: (1) the player was removed from the game (removed condition); (2) the player was helped off the field but later returned to play in the same game (returned condition); or (3) the player stayed in play (stayed condition). Following this, participants who initially answered "no" to the player experiencing a concussion were asked, "Now do you think this player experienced a concussion?" Participants who initially answered "yes" were asked, "Do you still think this player experienced a concussion?" The probability of switching to a different response (from yes to no, or from no to yes) was used as a measure of concussion reporting behaviour. 


\section{Accepted to Journal of Head Trauma Rehabilitation on 01/09/2019}

Percentage of change score. The percentage of change score was the conditional probability that participants would switch responses after being provided with additional information on how the suspected concussion in each video clip was managed (i.e., the player was removed, returned or stayed in the game). A change was noted if the participant switched responses following the additional information on concussion management. One percentage of change score was generated for each of the video clips and the percentage of change was summed for each of the three concussion management conditions (removed, returned, stayed), categorized into percentage of change from an initial response of yes and percentage of change from an initial response of no.

\section{Procedure}

Demographic information was collected from each participant who were then randomly assigned to either receive written information regarding RTP guidelines (RTP group $n=414$ ), e.g., "If a player is diagnosed with concussion they are not allowed to continue to play or return to play in the same game", or no information (No-RTP group $n=414$ ). Both groups were then shown 12 video clips taken from televised professional rugby games that depicted a player experiencing a potential concussion. After each clip, participants were asked whether they thought the player had sustained a concussion. Participants in both groups were then informed that the player had either been removed from play, returned to play, or stayed in play, and were then again asked whether or not they believed a concussion had taken place.

\section{Data Analysis}

A linear mixed model was built using the percentage of change scores (the probability of changing responses to whether a concussion had occurred based on additional information 


\section{Accepted to Journal of Head Trauma Rehabilitation on 01/09/2019}

about how the concussion had been managed) as the dependent variable. Group (RTP vs. NoRTP), condition (removed, returned, stayed), gender, and location (Australia, New Zealand, United Kingdom) were used as fixed factors. The model used a factorial ANOVA to examine effects between the fixed factors. Several models were generated and the best fitting model was identified using Schwarz's Bayesian Criterion (BIC) index for goodness of fit (lower BIC score $=$ better fit $)$.

\section{Results}

This study involved 828 participants of whom $57.6 \%(n=477)$ were male and $42.4 \%$ $(n=351)$ were female. Table 1 outlines demographic variables for the sample.

\section{Insert Table 1 here}

Over one quarter of the sample $(28 \%, 232 / 828)$ reported a history of one or more concussions. Males $(35 \%, \mathrm{n}=167)$ were significantly more likely to have experienced a concussion than females $(18 \%, n=65), \chi^{2}(1)=27.27, p<.01$. Males were also more likely to have played rugby $(22 \%, 185 / 828)$ than females $(1.5 \%, 13 / 828), \chi^{2}(4)=145.08, p<.01$, and be older, $\chi^{2}(4)=15.27, p<.01$.

The average probability of reporting a likely concussion, pooled over all videos, was $65.6 \%$, and was similar between males $(65.2 \%)$ and females $(65.8 \%)$. The likelihood of participants reporting a probable concussion was assessed using a factorial ANOVA. Group (RTP vs. No-RTP) was used as a between-subjects factor. Other fixed factors included were gender, concussion history, and experience with rugby. The ANOVA revealed no significant main effects for group, $F(1,827)=2.18, p>.10$, gender, $F(1,827)=0.15, p>.60$, concussion history, $F(1,827)=0.76, p>.30$, or experience with rugby, $F(1,827)=0.01, p>.90$, and no significant interactions. 


\section{Accepted to Journal of Head Trauma Rehabilitation on 01/09/2019}

The probability that participants would change their initial decision regarding whether or not a concussion had occurred based on additional information on post-injury management (i.e., the player was removed, returned, or stayed in the game) is shown in Figure 1 for females and males (i.e., percentage of change score). Data were analysed with a mixed-model ANOVA using a best-fitting covariance model (First-order Ante-dependence). Group (RTP vs. No-RTP), condition (removed, stayed, returned), initial concussion decision (yes/no), and gender were included as fixed factors. The percentage of change score was the dependent variable. There was a significant effect of gender, $F(1,827)=27.71, p<.01$, with females $(23.8 \%)$ reporting a higher percentage of change than males $(18.0 \%)$. The change score differed significantly across the three conditions, $F(1,827)=580.87, p<.01$. There was a significant interaction between condition (removed, stayed, returned) and initial concussion decision (yes/no). Participants were significantly more likely to switch from "yes" to "no" than "no" to "yes" in the stayed and returned conditions $(37.9 \%$ and $3.2 \%$ for stayed; $36.0 \%$ and $4.7 \%$ for returned), but more likely to switch from "no" to "yes" than "yes" to "no" in the removed condition (42.5\% and 1.1\%). Thus, participants constructed their final judgment of whether a concussion had occurred based on whether the player ultimately remained in the game or not.

The model also revealed a significant three-way interaction between gender, initial decision (yes/no) and condition, $F(1,827)=14.77, p<.01$, see Figure 1. Females in the removed condition were significantly more likely to change their decision to "yes" if they had initially answered "no" (49.2\%) than males (35.7\%). Females were also significantly more likely to change their decision to "no" if they had initially answered "yes" in the stayed condition (43.7\%) and returned condition (40.5\%) than males $(32.2 \%$ and $31.5 \%$, respectively). Thus, female participants were more likely to change their concussion judgments based on the additional information. Furthermore, males were less likely to change 


\section{Accepted to Journal of Head Trauma Rehabilitation on 01/09/2019}

and report a concussion (average of 18.0\%) in all three conditions than females (average of $23.0 \%)$. The removed condition generated higher percentage of change scores than the other two groups. The RTP guideline manipulation did not have a significant main effect or interaction effect with the percentage of change and other fixed factors.

Insert Figure 1 here

\section{Discussion}

This study examined whether viewers' judgements regarding potential concussive events in video clips of professional rugby matches were influenced by information regarding the post-injury management of players featured in the clips, or by information regarding RTP guidelines in sport. Results showed that providing participants with additional information as to whether the player had been removed, returned or stayed in the game had a significant effect on judgments of whether a concussion had taken place. If participants were told that a player had remained in the game or returned to play, they were more likely to change their judgment and say that a concussion had not occurred, whereas if they were told that a player had been removed they were more likely to change their judgment and say that a concussion had occurred. This effect was stronger for females than males. The findings also revealed that participants who were provided with information on RTP guidelines prior to viewing the video clips were no more likely than participants who were not provided with this information to change their decisions following the additional information on concussion management.

There is increasing evidence that media representations of concussion are a source of confusion for members of the general public in regard to concussive injuries and appropriate concussion management. ${ }^{3}$ Professional rugby players often do not leave the field following a concussion or are removed only briefly before being returned to the same game, and how this 


\section{Accepted to Journal of Head Trauma Rehabilitation on 01/09/2019}

behaviour is portrayed and discussed in sports media broadcasts is likely to influence how the general viewing public perceive and respond to concussive events in their own lives. ${ }^{13}$

Further, what constitutes a concussion is often inaccurately portrayed via televised media, where commentators have been found to use dramatic, entertaining and humorous terminology rather than factual and predictive account. ${ }^{13,25}$ The accuracy of representations of concussion and concussion management in sports media is critical, because if members of the public receive information that trivializes the seriousness or consequences of concussion or offers incorrect guidance on treatment recommendations, as this could influence their own health-seeking behaviour, with potentially serious implications for recovery.

Providing participants with information regarding the post-injury management of players featured in the video clips had a significant effect on participants' judgments of whether a concussion had taken place, particularly when they were informed that the player was removed from play. The findings of our study suggest that the public's perception of concussive events is powerfully influenced by information they receive following an injury. It is therefore concerning that previous content analyses of sports commentary related to concussion in professional rugby games identified that commentators rarely provide factual accounts of a player's symptoms or injury management and often focus on creating an entertaining atmosphere for the audience through drama and the player's response to being concussed. ${ }^{13,23}$ From a public health perspective, our findings highlight the need for sports media to also be informed and aware of their responsibility to ensure that the viewing public receives factually accurate and timely information surrounding concussion, as their description of these incidents may shape public understanding.

A gender effect was observed, with females being more likely to change their decisions following provision of additional information. This suggests that compared to 


\section{Accepted to Journal of Head Trauma Rehabilitation on 01/09/2019}

males, females tended to exercise more caution when additional information signalled risk, consistent with research suggesting that females prioritize risk prevention and are more likely to seek medical intervention than males. ${ }^{26,27}$ The findings may also be contextual in that rugby is a male dominated sport, both in terms of participation and spectatorship. ${ }^{20}$ Within our sample, males were almost 15 times more likely to have played rugby than females. Males may have therefore been more familiar with viewing televised rugby, and more familiar with the high rates of injuries that occur in the sport, and thus, more certain in their initial decisions. Furthermore, higher rates of concussion were reported among males than females in the current sample, and previous research e.g. Hux and colleagues ${ }^{3}$ suggests that people with experience of concussion tend to be better informed about brain injury than those without personal experience. Additional educational interventions targeting females through the popular media may help to increase females' confidence in their knowledge and ability to identify a suspected concussion.

Participants who were provided with information on RTP guidelines prior to viewing the videos were no more likely than participants who did not receive this information to change their decisions on whether a concussion had occurred in accordance with learning that the player in the clip has been removed, returned, or stayed in the game. Although this finding contradicts research suggesting that educational materials can improve knowledge of concussion and concussion management, ${ }^{28}$ it is possible that the RTP information had minimal impact because participants had a sufficient baseline knowledge of concussion protocols in sport to understand that a player who was removed from a game would have a higher chance of a diagnosis of concussion. It is also possible that participants in the RTP group read the brief information regarding RTP guidelines prior to watching the video clips but subsequently forgot or neglected to draw upon this information in making their decisions. 


\section{Accepted to Journal of Head Trauma Rehabilitation on 01/09/2019}

Providing the RTP group with additional reminders about the RTP guidelines throughout the clips may have prevented this possibility.

Several limitations of the study must be acknowledged. Participants self-selected into the study based on the title and a brief description, which informed participants they would be viewing a series of video clips taken from professional rugby games. Participants with a preexisting interest in rugby were potentially more likely to participate, which may limit the generalizability of findings. A further limitation is that although the footage used in the clips was taken from actual professional rugby games, the information provided regarding postconcussion management was communicated to participants via text on the computer screen rather than via voiceover, as would be the case in live sports broadcasts. Future research could enhance the ecological validity of the study by incorporating the concussion management information into spoken commentary for each of the videos, to more closely simulate the experience of watching authentic televised game footage. ${ }^{25}$

Notwithstanding these limitations, the findings of the current study have important implications for sports media broadcasting, and for educational interventions designed to improve public knowledge of concussion. Although there has been increasing interest in educating athletes,${ }^{29}$ coaches,${ }^{30}$ health care professionals,${ }^{31}$ parents ${ }^{32}$ and teachers ${ }^{33}$ in concussion and appropriate concussion management, there has not yet been a focus on increasing concussion knowledge among sports media. ${ }^{34}$ Although sports journalists are unlikely to have received formal medical training, it may be feasible to incorporate dedicated educational modules on concussion into professional development programs to address existing knowledge gaps and to raise awareness of the importance of providing the public with correct information on concussion. This in turn may improve the quality and accuracy of commentary, with potential benefits for perceptions and understanding of concussion in the wider community. 


\section{Accepted to Journal of Head Trauma Rehabilitation on 01/09/2019}

\section{Conclusion}

The primary goal of this study was to evaluate the influence of post-injury management information, similar to information that would commonly be delivered in sports media broadcasts, on viewers' perceptions of whether a possible concussive event had occurred. Although professional sports are primarily considered to be a source of entertainment, the findings of this study suggest that televised sports broadcasts may also be an influential source of information for the general public regarding concussion and postinjury management. Given that the causal effect between the provision of specific information about concussion and the consequences on participants' responses was directly addressed in this study, the findings offer valuable insights into policy setting for concussion management in the future. The results can also be used as a reference to develop educational interventions for sports media professionals that in turn, may improve concussion knowledge within the general public. 


\section{References}

1. Langlois, J. A., Rutland-Brown, W., \& Wald, M. M. (2006). The epidemiology and impact of traumatic brain injury: A brief overview. Journal of Head Trauma Rehabilitation, 21(5), 375-378. doi:10.1097/00001199-200609000-00001

2. McKinlay, A., Bishop, A., \& McLellan, T. (2011). Public knowledge of 'concussion' and the different terminology used to communicate about mild traumatic brain injury (MTBI). Brain Injury, 25(7-8), 761-766. doi:10.3109/02699052.2011.579935

3. Hux, K., Schram, C. D., \& Goeken, T. (2006). Misconceptions about brain injury: A survey replication study. Brain Injury, 20(5), 547-553.

doi:10.1080/02699050600676784

4. Koh, J. O., Cassidy, J. D., \& Watkinson, E. J. (2003). Incidence of concussion in contact sports: A systematic review of the evidence. Brain Injury, 17(10), 901-917. doi:10.1080/0269905031000088869

5. Powell, J. W., \& Barber-Foss, K. D. (1999). Injury patterns in selected high school sports: A review of the 1995-1997 seasons. Journal of Athletic Training, 34(3), 277284.

6. Gardner, A., Iverson, G. L., Levi, C. R., Schofield, P. W., Kay-Lambkin, F., Kohler, R. M., \& Stanwell, P. (2015). A systematic review of concussion in rugby league. British Journal of Sports Medicine, 49(8), 495-498. doi:10.1136/bjsports-2013-093102

7. NRL. (2016). Annual Report 2016. Australia: National Rugby League.

8. Noble, J. M., \& Hesdorffer, D. C. (2013). Sport-related concussions: A review of epidemiology, challenges in diagnosis, and potential risk factors. Neuropsychology Review, 23(4), 273-284. doi:10.1007/s11065-013-9239-0 
9. Marshall, S., Bayley, M., McCullagh, S., Velikonja, D., Berrigan, L., Ouchterlony, D., \& Weegar, K. (2015). Updated clinical practice guidelines for concussion/mild traumatic brain injury and persistent symptoms. Brain Injury, 29(6), 688-700. doi:10.3109/02699052.2015.1004755

10. ARU. (2015). Medical and Safety Recommendations. Retrieved from http://www.aru.com.au/Portals/33/Policy\%20Register/Safe\%20Practices/ARU\%20Me dical\%20and\%20Safety\%20Recommendations_2015.pdf

11. Guskiewicz, K. M., Bruce, S. L., Cantu, R. C., Ferrara, M. S., Kelly, J. P., McCrea, M., .. . McLeod, T. C. V. (2004). National Athletic Trainers' Association position statement: Management of sport-related concussion. Journal of Athletic Training, 39(3), 280.

12. McCrory, P., Meeuwisse, W. H., Aubry, M., Cantu, B., Dvořák, J., Echemendia, R. J., . . Raftery, M. (2013). Consensus statement on concussion in sport: The 4th International Conference on Concussion in Sport held in Zurich, November 2012. British Journal of Sports Medicine, 47(5), 250-258. doi:10.1136/bjsports-2013-092313

13. McLellan, T., \& McKinlay, A. (2011). Does the way concussion is portrayed affect public awareness of appropriate concussion management: The case of rugby league. British Journal of Sports Medicine, 45(12), 993-996. doi:10.1136/bjsm.2011.083618

14. Iverson, G. L., Brooks, B. L., Collins, M. W., \& Lovell, M. R. (2006). Tracking neuropsychological recovery following concussion in sport. Brain Injury, 20(3), 245252. doi:10.1080/02699050500487910

15. Hollis, S. J., Stevenson, M. R., McIntosh, A. S., Shores, E. A., \& Finch, C. F. (2012). Compliance with return-to-play regulations following concussion in Australian schoolboy and community rugby union players. British Journal of Sports Medicine, 46(10), 735-740. doi:10.1136/bjsm.2011.085332 
16. McKinlay, A. (2014). Long-term outcomes of traumatic brain injury in early childhood. Australian Psychologist, 49(6), 323-327. doi:10.1111/ap.12084

17. Guskiewicz, K. M., Marshall, S. W., Bailes, J., McCrea, M., Cantu, R. C., Randolph, C., \& Jordan, B. D. (2005). Association between recurrent concussion and late-life cognitive impairment in retired professional football players. Neurosurgery, 57(4), 719-726. doi:10.1227/01.NEU.0000175725.75780.DD

18. McCrea, M., Hammeke, T., Olsen, G., Leo, P., \& Guskiewicz, K. (2004). Unreported concussion in high school football players: Implications for prevention. Clinical journal of sport medicine, 14(1), 13-17.

19. Haarbauer-Krupa, J., Comstock, R. D., Lionbarger, M., Hirsch, S., Kavee, A., Lowe, B. (2018). Healthcare professional involvement and RTP compliance in High School Athletes with Concussion. Brain Injury, DOI:10.1080/02699052.2018.1482426.

20. Anderson, E., \& Kian, E. M. (2012). Examining media contestation of masculinity and head trauma in the National Football League. Men and Masculinities, 15(2), 152-173. doi:10.1177/1097184X11430127

21. Sanderson, J., Weathers, M., Grevious, A., Tehan, M., \& Warren, S. (2016). A hero or sissy? Exploring media framing of NFL quarterbacks injury decisions. Communication \& Sport, 4(1), 3-22. doi:10.1177/2167479514536982

22. Messner, M. A. (2002). Taking the field: Women, men, and sports (Vol. 4). Minneapolis: University of Minnesota Press.

23. Kennard, M., McLellan, T., \& McKinlay, A. (2017). Sports media representations of concussions in the National Rugby League. Australian Psychologist. doi:10.1111/ap.12272

24. Qualtrics. (2015). Qualtrics (May, August, September 2015) [Computer software]. Provo, UT: Qualtrics. Retrieved from http://www.qualtrics.com. 
25. Kennard, M., McLellan T., \& McKinlay A. (2018). Sports Media Representations of Concussions in the National Rugby League. Australian Psychologist, 53(1), 97-102. doi: 10.1111/ap.12272

26. Harris, C. R., Jenkins, M., \& Glaser, D. (2006). Gender differences in risk assessment: Why do women take fewer risks than men? Judgment and Decision making, 1(1), 48.

27. Tong, V., Raynor, D. K., \& Aslani, P. (2014). Gender differences in health and medicine information seeking behaviour - A review. Journal of the Malta College of Pharmacy Practice, 20, 14-16.

28. Miyashita, T. L., Timpson, W. M., Frye, M. A., \& Gloeckner, G. W. (2013). The impact of an educational intervention on college athletes' knowledge of concussions. Clinical journal of sport medicine, 23(5), 349-353. doi:10.1097/JSM.0b013e318289c321

29. Bramley, H., Patrick, K., Lehman, E., \& Silvis, M. (2012). High school soccer players with concussion education are more likely to notify their coach of a suspected concussion. Clinical pediatrics, 51(4), 332-336. doi:10.1177/0009922811425233

30. Rivara, F. P., Schiff, M. A., Chrisman, S. P., Chung, S. K., Ellenbogen, R. G., \& Herring, S. A. (2014). The effect of coach education on reporting of concussions among high school athletes after passage of a concussion law. The American journal of sports medicine, 42(5), 1197-1203. doi:10.1177/0363546514521774

31. Sullivan, S. J., Alla, S., Lee, H., Schneiders, A. G., Ahmed, O. H., \& McCrory, P. R. (2012). The understanding of the concept of 'rest' in the management of a sports concussion by physical therapy students: A descriptive study. Physical Therapy in Sport, 13(4), 209-213. doi:10.1016/j.ptsp.2011.10.004

32. Chrisman, S. P., Schiff, M. A., Chung, S. K., Herring, S. A., \& Rivara, F. P. (2014). Implementation of concussion legislation and extent of concussion education for 


\section{Accepted to Journal of Head Trauma Rehabilitation on 01/09/2019}

athletes, parents, and coaches in Washington State. The American journal of sports medicine, 42(5), 1190-1196. doi:10.1177/0363546513519073

33. Case, R. J. L., Starkey, N. J., Jones, K., Barker-Collo, S., \& Feigin, V. New Zealand teachers' understanding of childhood mild traumatic brain injury: Investigating and enhancing teacher knowledge and practice. New Zealand Journal of Educational Studies, 52(1), 159-176. doi:10.1007/s40841-017-0080-5

34. Ahmed, O. H., Blake, T., \& Hall, E. E. (2016). Educating the masses: Suggestions for improving online concussion information via the mainstream media. Concussion, 2(1). doi:10.2217/cnc-2016-0026 
Table 1

Demographic information for the sample

\begin{tabular}{|c|c|c|}
\hline & Male $(n=477)$ & Female $(n=351)$ \\
\hline \multicolumn{3}{|l|}{ Location } \\
\hline New Zealand & $6.7 \%(n=32)$ & $6.6 \%(n=23)$ \\
\hline UK & $59.1 \%(n=282)$ & $57.3 \%(n=201)$ \\
\hline Australia & $34.2 \%(n=163)$ & $36.2 \%(n=127)$ \\
\hline \multicolumn{3}{|l|}{ Age } \\
\hline $18-20$ & $55.0 \%(n=5)$ & $44.0 \%(n=4)$ \\
\hline $21-29$ & $51.0 \%(n=17)$ & $48.0 \%(n=16)$ \\
\hline $30-39$ & $45.0 \%(n=45)$ & $54.0 \%(n=54)$ \\
\hline $40-49$ & $50.0 \%(n=81)$ & $49.0 \%(n=80)$ \\
\hline $50+$ & $62.0 \%(n=329)$ & $37.0 \%(n=197)$ \\
\hline \multicolumn{3}{|l|}{ Concussion History } \\
\hline Yes & $35.0 \%(n=167)$ & $18.5 \%(n=65)$ \\
\hline No & $65.0 \%(n=310)$ & $81.5 \%(n=286)$ \\
\hline \multicolumn{3}{|l|}{ Experience with Rugby } \\
\hline Never Played & $61.2 \%(n=292)$ & $96.3 \%(n=338)$ \\
\hline Played one season & $10.3 \%(n=49)$ & $1.4 \%(n=5)$ \\
\hline $\begin{array}{l}\text { Played more than one season but no } \\
\text { longer play }\end{array}$ & $25.8 \%(n=123)$ & $0.5 \%(n=2)$ \\
\hline Currently playing social games & $2.7 \%(n=13)$ & $1.4 \%(n=5)$ \\
\hline Currently playing competitive games & $0.0 \%(n=0)$ & $0.003 \%(n=1)$ \\
\hline
\end{tabular}


Figure 1: Change Probability by Condition and Initial Decision.

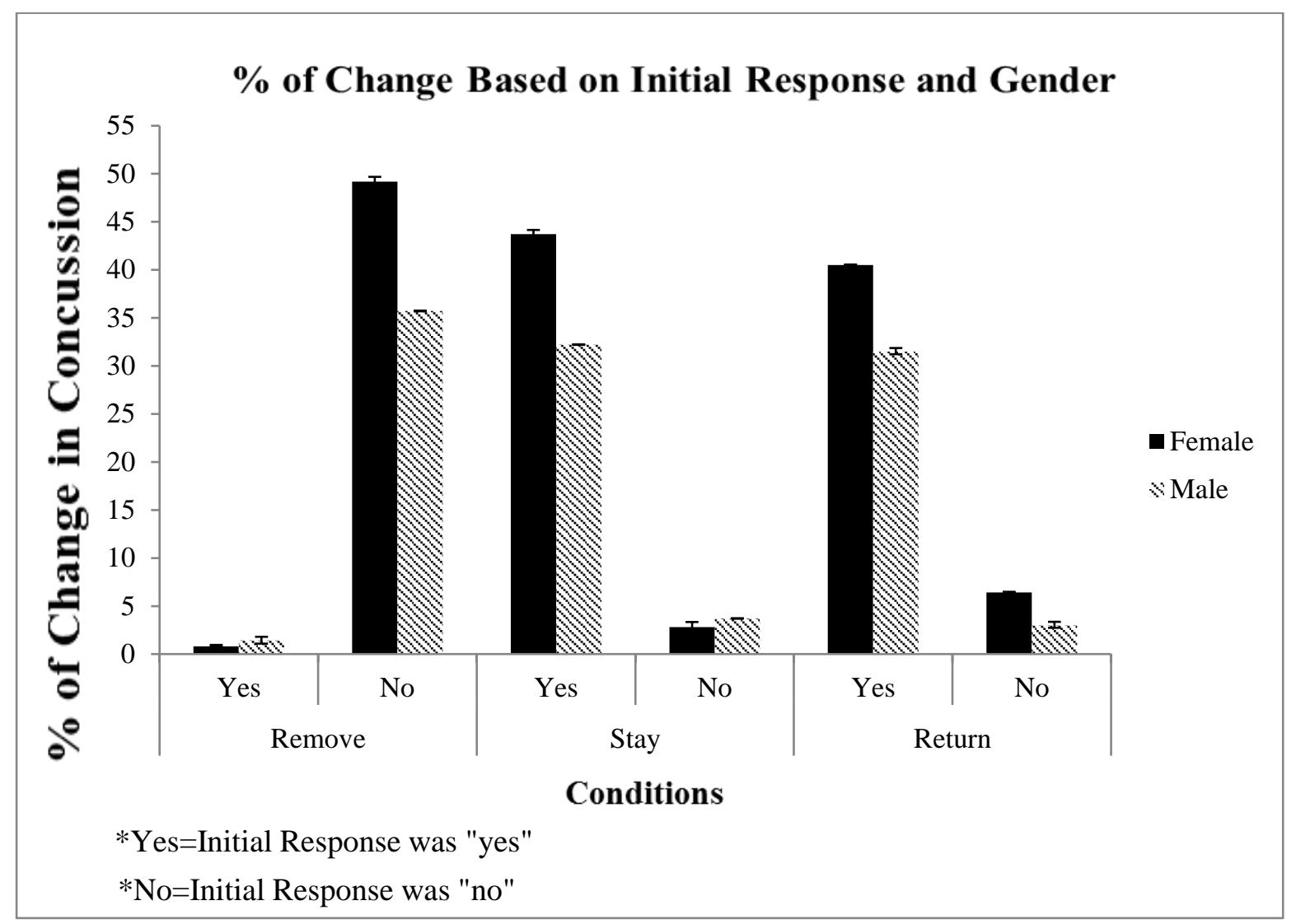

